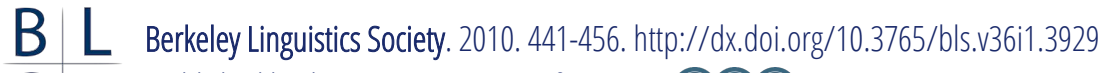

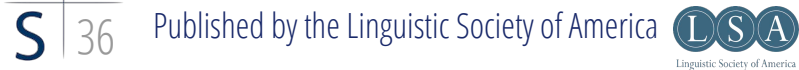

\section{Person Indexicals in Uyghur Indexical Shifting}

\author{
YASUTADA SUDO \\ Massachusetts Institute of Technology
}

\section{$1 \quad$ Introduction}

Every natural language known so far has indexicals - expressions whose meanings are dependent on the context of utterance (e.g. I, you, here, now, etc. in English). An intriguing semantic property of indexicals was pointed out by Kaplan (1989): their referents are fixed regardless of the syntactic environments they are in. Especially, they are insensitive to modals unlike definite descriptions. For example, in the examples below, the word I obligatorily refers to the speaker, even though it is in modal contexts.

(1) a. John thinks that I am a linguist

b. If I were a biologist, I wouldn't be a linguist

This fact led Kaplan (1989) to conjecture that indexicals always refer to the actual context of utterance, and moreover that there is no operator in natural language that manipulate contexts. He called such (supposedly non-existent) context-shifting operators monsters. The logic here is that if a context-shifting operator did exist, indexicals under its scope would be interpreted relative to non-actual contexts. In this paper, we call such phenomena indexical shifting.

Contrary to Kaplan's (1989) conjecture, however, Schlenker $(1999,2003)$ pointed out that there are languages with indexical shifting. Specifically, in Amharic attitude reports, indexicals may be interpreted relative to the reported context, rather than the current context of utterance, as shown by the examples below.

(2) Amharic

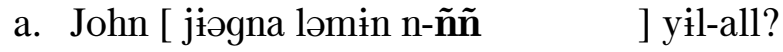

John [ hero why COP.PRES-1s ] says-3sm

'Why does John say that $\{\mathrm{I}$ am, he is $\}$ a hero?'

(Anand 2006:82) 


\section{Yasutada Sudo}

b. [ min amt'-a ] ind-al-ə-ññ al-səmma-hu-mm
[ what bring.IMPER-2m ] COMP-say.PF-3m-1sO NEG-hear.PF-1s-NEG
'I didn't hear what he told me to bring.'

In addition, recent studies show that Amharic is not the only language with indexical shifting. Specifically, Navajo (Speas 1999), Zazaki, Slave (Anand and Nevins 2004; Anand 2006), Catalan Sign Language (Quer 2005), Nez Perce (Deal 2008) and Matses (Ludwig et al. to appear)) are reported to allow indexical shifting in attitude contexts. Based on these languages, it is now considered that monsters in fact do exist in natural language, contrary to Kaplan's (1989) surmise (Schlenker 1999, 2003; Anand and Nevins 2004; Anand 2006 among others). ${ }^{1}$

One of the goals of the present paper is to provide novel data of indexical shifting from yet another language, (Modern) Uyghur. ${ }^{2}$ Focusing on the interpretation of 1 st and 2nd person singular indexicals, we observe two peculiar features of Uyghur indexical shifting: (i) that 1 st person indexicals are obligatorily de se, while 2nd person indexicals are not obligatorily de se in the sense explained below; and (ii) that shifted 2nd person pronouns are not allowed under certain attitude verbs, while shifted 1st person pronouns are always licensed. We propose a formal semantic account of both phenomena.

This paper is organized as follows. In Section 2, the basic facts about Uyghur indexical shifting are introduced. The semantic properties of shifted indexicals are discussed in Section 3, a formal semantic account of which is proposed in the subsequent section. We look at the behavior of person indexicals under various kinds of attitude verbs in Section 5, which we claim follows from the lexical semantics of the attitude verbs and can be given a straightforward account in our theory presented in Section 4. In Section 6, we review a previous account of similar facts in Slave due to Anand and Nevins (2004) and Anand (2006), and claim that our analysis is conceptually better.

\section{$2 \quad$ Uyghur Indexical Shifting}

Just as in the other languages mentioned in Section 1, indexical shifting in Uyghur is confined to complement clauses to attitude verbs, but Uyghur is special in that it has two kinds of complement clauess that differ in whether indexical shifting takes place. More specifically, some attitude verbs only take nominalized complement clauses, others only take finite complement clauses, and still others are compatible with both types. For example, the verb $d e$ - 'say, tell' can take either.

\footnotetext{
${ }^{1}$ See von Stechow (2002) and Ogihara (2006) for monster-free theories.

${ }^{2}$ Uyghur is an eastern Turkic language spoken by 8-10 million speakers mainly in the Xinjiang Autonomous Region of China. It possesses the usual Turkic features including SOV word order, scrambling, radical pro-drop, highly agglutinative verbal morphology, allomorphy involving vowel harmony, and case suffixes on nouns (see Hahn 1991 and De Jong 2007 for descriptive grammars).
} 
a. Nominalized Complement Clause

Ahmet [ profesor-ning kit-ken-lik-i-ni ] di-di

Ahmet [ professor-GEN leave-REL-NMLZ-3-ACC ] say-PAST.3

'Ahmet said that the professor left'

b. Finite Complement Clause

Ahmet [ profesor ket-ti ] di-di

Ahmet [ professor.NOM leave-PAST.3 ] say-PAST.3

'Ahmet said that the professor left'

Interestingly enough, indexical shifting is basically obligatory in finite complement clauses to attitude verbs (see Shklovsky and Sudo to appear for some complications), but never observed in nominalized complement clauses, as illustrated by the following examples.

a. Nominalized Complement Clause

Ahmet [ mening kit-ken-lik-im-ni ] di-di

Ahmet [ 1 SG.GEN leave-REL-NMLZ-1SG-ACC ] say-PAST.3

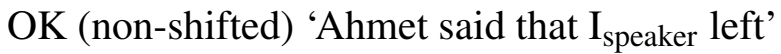

* (shifted) 'Ahmet ${ }_{i}$ said that he ${ }_{i}$ left'

b. Finite Complement Clause

Ahmet [ men ket-tim ] di-di

Ahmet [ 1SG leave-PAST.1SG] say-PAST.3

* (non-shifted) 'Ahmet said that $\mathrm{I}_{\text {speaker }}$ left'

OK (shifted) 'Ahmet ${ }_{i}$ said that he ${ }_{i}$ left' $^{\prime}$

These sentences are not synonymous. In (4a), mening 'my' refers to the speaker of the entire sentence, just like in English, while in (4b), men 'I' obligatorily refers to the attitude holder Ahmet, rather than the speaker.

At this point, one might wonder whether the embedded clause in (4b) is an instance of direct quotation. However, there are several pieces of evidence showing that finite complement clauses need not be quotational. ${ }^{3}$. For example, the finite complement in (5) contains a wh-phrase taking the matrix scope, which guarantees that the embedded clause is not a quotation, because wh-quantification into quotations is generally impossible. Nonetheless, the first person indexicals obligatorily refer to the attitude holder Tursun.

(5) Tursun [ men kim-ni kör-dim ] di-di?

Tursun [ 1SG who-ACC see-PAST.1SG ] say-NEG-PAST.3

'Who did $\operatorname{Tursun}_{i}$ say he $_{i}$ saw?'

${ }^{3}$ Due to space limitations, we present just one argument here and refer the interested reader to Shklovsky and Sudo (to appear). 


\section{Yasutada Sudo}

We observed in this section that Uyghur morphosyntactically distinguishes shifting and non-shifting complement clauses to attitude verbs, unlike in the languages known so far. For the rest of this paper, we exclusively look at 1st and 2nd person indexicals in shifting environments, but it should be noted here that certain temporal indexicals also shift in the same way, while locative indexicals and demonstratives never do in Uyghur.

\section{3 (Non-)Obligatory $\mathrm{De}$ Se Readings of Shifted Indexicals}

This section discusses the semantic properties of shifted indexicals in Uyghur. In particular, we observe that shifted 1 st person indexicals are obligatorily de se, while shifted 2nd person indexicals need not be 2 nd person de se (or de te).

By de se interpretations of pronouns, we mean the following. In the de se construal, a pronoun refers to the individual that the attitude holder identifies as himself, not just that we, as a third party, identify as him (Lewis 1979). That this is a linguistically relevant distinction is shown by the contrast between 3rd person pronouns and PRO in obligatory control constructions in English. That is, English 3rd person pronouns are generally ambiguous between de se and non-de se readings, while PRO is obligatorily de se (Chierchia 1989).

(6) Context: John is so drunk that he has forgotten that he is a candidate in the election. He watches someone on TV and finds that that person is a terrific candidate, who should definitely be elected. Unbeknownst to John, the candidate he is watching on TV is John himself.

a. $\mathrm{John}_{i}$ hopes that he $\mathbf{e}_{i}$ will be elected

b. \#John $i$ hopes $\mathbf{P R O}_{i}$ to be elected

(Schlenker 2003:61)

There is a comparable reading for pronouns denoting the hearer, which is called 2nd person de se or de te. That is, de te pronouns denote the individual that the attitude holder identifies as the person she is/was talking to. Again PRO in English object control is sensitive to this distinction.

(7) Context: John is hosting a party. He hears that a certain waiter named Bill is being a nuisance. John tells the nearest waiter, "Bill has to go." Unbeknownst to him, he's talking to Bill.

a. John told Bill $_{i}$ that he $\mathbf{h}_{i}$ had to leave

b. \#John told Bill $\mathbf{P R O}_{i}$ to leave

(Anand 2006:16)

With this in mind, we now observe that Uyghur shifted 1st person pronouns are obligatorily de se, just as PRO in English. The logic is the same as above: the given context only supports the non-de se readings of the pronouns and an infelicity indicates that the pronoun can only be read de se. Here, the contrast is illustrated 
by shifted 1 st person pronoun men and a 3rd person pronoun (a 3 rd person reflexive or pro) in a nominalized complement clause which is not a shifting environment.

(8) Context: Ahmet took an exam, and later saw the top 10 scorers with the respective ID numbers. He forgot his own ID number, so didn't know who was who. Pointing to the No.1 scorer, he remarked "This guy is very smart!" But it turned out that he was talking about himself.

Ahmet üzi ik-ken-lik-i-ni bil-mey,

Ahmet himself COP-REL-NML-3sg-ACC know-NEG,

'Ahmet did not know that it was him, but'

a. \# Ahmet [ men bek aqriliq] di-di

Ahmet [ 1sg very smart ] say-PAST.3

'Ahmet ${ }_{i}$ said that he ${ }_{i}$ is very smart'

b. Ahmet [(üz-i-ning) bek aqriliqik-ken-lik-i-ni ] di-di Ahmet [ (self-3-GEN) very smart COP-REL-NML-3sg-ACC ] say-PAST.3

'Ahmet ${ }_{i}$ said that he ${ }_{i}$ is very smart'

On the other hand shifted, 2nd person pronouns are not obligatorily de te.

(9) Context: Muhemmet is hosting a party. He hears that a certain waiter named John is being a nuisance. Muhemmet tells the nearest waiter, "John should go home." Unbeknownst to him, he's talking to John.

a. Muhemmet John-gha [pro öy-ge kit-sh-ing kirek ] di-di Muhemmet John-DAT [ pro home-DAT leave-GER-2sg should ] say-PAST.3

'Muhemmet told $\mathrm{John}_{i}$ that he ${ }_{i}$ should go home'

b. Muhemmet John-gha [u-ning öy-ge kit-sh-i kirek ik-ken-lik-i-ni Muhemmet John-DAT [ 3sg-GEN house-to leave-GER-3 should COP-REL-NML-3-ACC ] di-di ] say-PAST.3

'Muhemmet told $\mathrm{John}_{i}$ that he $i$ should go home'

It is even possible to be explicit about Muhemmet's epistemic state as in the following example, which is felicitous in the same context as above.

(10) Muhemmet John-ni tunu-imay, uninggha [sen öy-ge kit-sh-ing Muhemmet John-ACC recognize-NEG, he.DAT [2sg house-DAT leave-GER-2sg kirek ] di-di should ] say-PAST.3

'Muhemmet did not recognize $\mathrm{John}_{i}$, and told him ${ }_{i}$ that he ${ }_{i}$ should go home'

This behavior of Uyghur 2nd person pronouns in shifted contexts is different from other languages with indexical shifting such as Amharic and Zazaki, in which both shifted 1st and 2nd person pronouns are obligatory de se or de te, as Anand (2006) discusses. We will come back to this in Section 6. 


\section{Yasutada Sudo}

\section{$4 \quad$ Analysis of Indexical Shifting}

In this section, we present a formal semantic analysis of indexical shifting. We adopt Anand's (2006) analysis to a large extent, although there are some differences.

Firstly, we model a (possible) context of utterance as an additional index $c$ to which the interpretation function $\llbracket \cdot \rrbracket$ is relativized. As we are only interested in indexical shifting of person indexicals, we assume that contexts are triples consisting of two individuals and a world $\left(c=\left\langle a_{c}, h_{c}, w_{c}\right\rangle\right)$. By assumption, indexicals make reference to the context index.
a. $\llbracket \mathrm{I} \rrbracket_{g}^{c}=a_{c}$
b. $\llbracket \mathrm{you} \rrbracket_{g}^{c}=h_{c}$
c. $\llbracket$ we $\rrbracket_{g}^{c}=$ the salient group of individuals that includes $a_{c}$

Also, we postulate possible evaluation indices $i$ in the object language (cf. Ty2 of Gallin 1975; see also Percus 2000; Keshet 2008), whose denotations are assumed to be of the same semantic type as context indices (cf. von Stechow and Zimmermann 2005; Anand 2006; pace Kaplan 1989).

In general, modals are quantifies over indices. For examples, the universal deontic modal must is of type $\langle s t, s t\rangle$ and given the following meaning.

(12) For any $\llbracket \phi \rrbracket_{g}^{c}$ of type $\langle s, t\rangle$,

$\llbracket$ must $\phi \rrbracket_{g}^{c}=\lambda i$. for any $\left\langle a_{i}, h_{i}, w_{j}\right\rangle$ such that the relevant rules are obeyed in $w_{j}, \llbracket \phi \rrbracket_{g}^{c}\left(\left\langle a_{i}, h_{i}, w_{j}\right\rangle\right)=1$

It should be remarked here that modals never manipulate the context index, which ensures indexicals' insensitivity to modality discussed in Section 1.

In order to account for indexical shifting, we claim that there is a 'monstrous' lexical item $\mathcal{M}$ in Uyghur that manipulates the context index. Notice that this operator should not be attitude verbs, because indexical shifting never takes place in nominalized complements clauses although the same attitude verbs are employed as in finite complement constructions (pace Schlenker 1999, 2003). Instead we assume that $\mathcal{M}$ is a covert operator that only and always appears in finite complements and never in nominalized complements (see Shklovsky and Sudo to appear for its syntax). $\mathscr{M}$ performs the following operation.

$$
\text { (13) For any } \llbracket \phi \rrbracket_{g}^{c} \text { of type } t, \quad \llbracket \mathcal{M}_{\mathrm{i}} \phi \rrbracket_{g}^{c}=\llbracket \phi \rrbracket_{g}^{g(\mathrm{i})}
$$

Just as other lexical items in the current system, $\mathcal{M}$ is assumed to take an object language index as its first argument as indicated by the subscript. Also for compositional purposes, we take (13) to be a new compositional operation triggered by this particular lexical item (cf. 'Monstrous Functional Application' of von Stechow and Zimmermann 2005; Anand 2006). 
The last ingredient necessary for indexical shifting is the meaning of attitude verbs. Following the standard Hintikka semantics for attitude verbs, we assume that they are modals. Recall, however, that in the present system, modals quantify over triples consisting of two individuals and a possible world, rather than just possible worlds. We claim that unlike non-attitude modals, attitude verbs change the individual coordinates to new ones, namely, de se and de te individuals respectively. For example, the meaning of tell looks like the following.

$$
\begin{aligned}
& \text { For any } \llbracket \phi \rrbracket_{g}^{c} \text { of type }\langle s, t\rangle, \\
& \llbracket \text { tell } \phi \rrbracket_{g}^{c}=\lambda y . \lambda x . \lambda i . \quad \forall j \in \operatorname{SAY}_{x, y, i} \llbracket \phi \rrbracket_{g}^{c}(j)=1
\end{aligned}
$$

where $j \in \mathrm{SAY}_{x, y, i}$ iff

$$
\left(j=\left\langle a_{j}, h_{j}, w_{j}\right\rangle\right)
$$

a. $w_{j}$ is compatible with what $x$ tells $y$ in $w_{i}$;

b. $a_{j}$ is the individual in $w_{j}$ that $x$ identifies in $w_{i}$ as himself;

c. $h_{j}$ is the individual in $w_{j}$ that $x$ identifies in $w_{i}$ as the person $x$ is talking to

The above ingredients are sufficient to achieve indexical shifting. More concretely, the monster $\mathcal{M}$ changes the context index to the one that is quantified over by the attitude verb, and therefore, any indexical under the scope of the monster gets interpreted relative to the new index and may refer to an individual other than the current speaker or hearer.

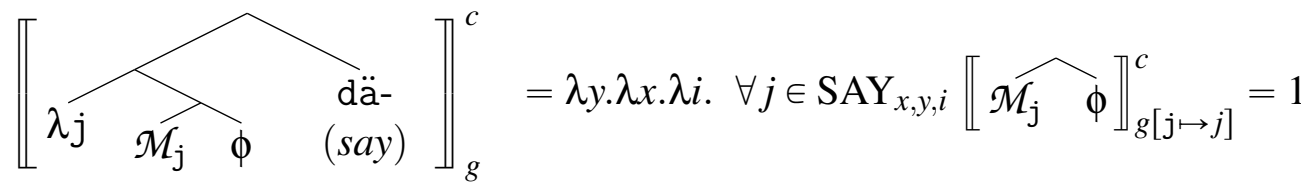

$$
\begin{aligned}
& =\lambda y . \lambda x . \lambda i . \quad \forall j \in \mathrm{SAY}_{x, y, i} \llbracket \phi \rrbracket_{g[j \mapsto j]}^{j}=1
\end{aligned}
$$

There are two auxiliary assumptions that should be made explicit here. The matrix clause is always of type $\langle s, t\rangle$ and is evaluated against the current context of utterance. Also, $\mathcal{M}$ must take the index of the closest abstraction ( $j$ in the above case), just like adverbs and predicates (cf. Percus 2000; Keshet 2008), and can never be de re.

Now we are ready to explain the difference between shifted 1st and 2 nd person indexicals. Recall that in Uyghur the former are obligatorily de se, while the latter are not. The following simple semantics for 1st person indexicals as a projection function, which we proposed for English in (11), yields the obligatory de se reading, because the first individual coordinate of a shifted context index is required to be the de se individual by the semantics of the attitude verb.

$$
\llbracket \mathrm{men} \rrbracket_{g}^{c}=a_{c}
$$

On the other hand, shifted 2nd person indexicals in Uyghur require a further treatment, because they are not obligatorily de te and therefore cannot denote the 


\section{Yasutada Sudo}

de te individual coordinate of a shifted context index. To this end, we claim that they are disguised definite descriptions containing a 1st person indexical. Being definite descriptions, they take an index as their first argument.

$$
\llbracket \operatorname{sen} \rrbracket_{g}^{c}=\lambda i \text {. the individual in } w_{i} \text { that } a_{c} \text { is/was talking to in } w_{i}
$$

It is assumed here that this definite description can be read de re, just like other normal definite descriptions, in which case sen takes the matrix index. This is illustrated by the following schematic example.

$$
\lambda i \text { John told Mary }\left[\text { that } \lambda j \mathcal{M}_{j} \ldots\left[\text { sen }_{i}\right] \ldots\right]
$$

Thus sen 'you' in (18) is interpreted as the individual in $w_{i}$ that $a_{c}$ was talking to in $w_{i}$, and there is no requirement that John be able to identify the same individual as the person he was talking to. It is also allowed for the index sen takes to be $j$, in which case it receives a de te reading. ${ }^{4}$

\section{$5 \quad$ Restrictions on Shifted 2nd Person Pronouns}

In this section, we turn to another difference between 1st and 2nd person indexicals in Uyghur indexical shifting. That is, certain attitude verbs shift only 1 st person indexicals and shifted 2nd person indexicals under them are infelicitous. Furthermore, we claim that these two classes of attitude verbs are not determined arbitrarily, but are semantic natural classes. Specifically, under verbs of communication whose subject is the language user and the other argument is the hearer, both 1st and 2 nd person indexicals undergo indexical shifting.

de- (say, tell)

a. Ahmet [ pro kim-ni jaxshi kör-imen ] di-di? Ahmet [ pro who-ACC well see-IMPERF.1sg ] say-PAST.3

'Who did Ahmet say that he likes?'

b. Ahmet Aygül-ge [pro kim-ni jaxshi kör-isen ] di-di? Ahmet Aygül-DAT [ pro who-ACC well see-IMPERF.2sg ] say-PAST.3 'Who did Ahmet told Aygül that she likes?'

(20) sözle- (speak, talk)

a. Ahmet [ pro kim-ni jaxshi kör-imen dep ] sözli-di? Ahmet [ pro who-ACC well see-IMPERF.1sg C ] speak-PAST.3 'Who did Ahmet say that he likes?'

\footnotetext{
${ }^{4}$ Strictly speaking, for sen to receive the correct interpretation in this construal, the world coordinate of the index sen combines with should be a world compatible with what John believes, rather than a world compatible with what John told Mary. This is a general problem of this type of account of de re/de dicto (cf. Geurts 1999).
} 
b. Ahmet Aygül-ge [pro kim-ni jaxshi kör-isen dep] sözli-di? Ahmet Aygül-DAT [ pro who-ACC well see-IMPERF.2sg C ] speak-PAST.3 'Who did Ahmet told Aygül that she likes?'

(21) maxtan- (brag)

a. Ahmet Aygül-ge [ pro kim-ni kör-dim dep ] maxtan-di? Ahmet Aygül-DAT [ pro who-ACC saw C ] brag-PAST.3 'Who did Ahmet brag to Aygül that he met?'

b. Ahmet Aygül-ge [ men sen-din igiz dep ] maxtan-di Ahmet Aygül-DAT [ 1sg 2sg-from tall C ] brag-PAST.3

'Ahmet bragged that he is taller than Aygül'

(22) qayil qil- (persuade, convince)

a. Ahmet Aygül-ni [ pro kim-ni kör-imen dep ] qayil Ahmet Aygül-ACC [ pro who-ACC see-IMPERF.1sg C ] convince qil-di? do-PAST.3

'Who did Ahmet convince Aygül that he should meet?'

b. Ahmet Aygül-ni [ pro kim-ni kör-isen dep ] qayil Ahmet Aygül-ACC [ pro who-ACC see-IMPERF.2sg C ] convince qil-di? do-PAST.3

'Who did Ahmet convince Aygül that she should meet?'

(23) aghrin- (complain)

a. Ahmet Aygül-ge [pro kim-ni kör-dim dep] aghrin-di? Ahmet Aygül-DAT [ pro who-ACC see-PAST.1sg C ] complain-PAST.3 'Who did Ahmet complain to Aygül that he met?'

b. Ahmet Aygül-ge [pro kim-ni kör-ding dep] aghrin-di? Ahmet Aygül-DAT [ pro who-ACC see-PAST.2sg C ] complain-PAST.3 'Who did Ahmet complain to Aygül that she met?'

(24) wede qal- (promise)

a. Ahmet Aygül-ge [prokim-ni söy-imen dep]wede qil-di? Ahmet Aygül-DAT [ pro who-ACC kiss-IMPERF.1sg C ] promise do-PAST.3 'Who did Ahmet promise Aygül to kiss?'

b. Ahmet Aygül-ge [ pro qaysi imtihan-din öt-isen dep ] Ahmet Aygül-DAT [ pro which test-from pass-IMPERF.2sg C ] wede qil-di? promise do-PAST.3

'Which test did Ahmet promise Aygül that she would pass' 


\section{Yasutada Sudo}

Unlike verbs of communication, verbs of believing shift only 1 st person indexicals and 2nd person indexicals under these verbs are infelicitous. Notice that with those verbs, finite complement clauses simply cannot contain a shifted 2 nd person indexical and there is no alternative acceptable interpretation.

(25) bil- (believe, know)

a. Ahmet [ pro kim-ni jaxshi kör-imen dep ] bil-du? Ahmet [ pro who-ACC well see-IMPERF.1sg C ] believe-IMPERF.3 'Who does Ahmet believe that he likes?'

b. *Ahmet [ pro kim-ni jaxshi kör-isen dep ] bil-du? Ahmet [pro who-ACC well see-IMPERF.2sg C ] believe-IMPERF.3

(26) oyla- (think)

a. Ahmet [ pro kim-ni jaxshi kör-imen dep ] oyla-du? Ahmet [ pro who-ACC well see-IMPERF.1sg C ] think-IMPERF.3 'Who does Ahmet think he likes?'

b. *Ahmet [ pro kim-ni jaxshi kör-isen dep ] oyla-du? Ahmet [ pro who-ACC well see-IMPERF.2sg C ] think-IMPERF.3

(27) ansir- (worry)

a. Ahmet [ pro qaysi imitihan-din ötül-ma-imen dep] ainsir-di? Ahmet [ pro which test-from pass-NEG-IMPERF.1sg C ] worry-PAST.3 'Which test does Ahmet worry that he didn't pass?'

b. *Ahmet [ pro qaysi imitihan-din ötül-ma-isen dep] ainsir-di? Ahmet [pro which test-from pass-NEG-IMPERF.2sgC ] worry-PAST.3

(28) ümid qil- (hope)

a. Ahmet [ pro kim-ni kör-imen dep ] ümid qil-du? Ahmet [ pro who-ACC see-IMPERF.1sg C ] hope do-IMPERF.3 'Who does Ahmet want to meet?'

b. *Ahmet [ pro kim-ni kör-isen dep ] ümid qil-du? Ahmet [pro who-ACC see-IMPERF.2sg C ] hope do-IMPERF.3

(29) xejal qil- (dream about)

a. Ahmet [ pro qaysi imtihan-din öt-tim dep] xejal qil-di? Ahmet [ pro which test-from pass-PAST.1sg C ] dream do-PAST.3 'Which test did Ahmet dream about passing?'

b. *Ahmet [ pro qaysi imtihan-din öt-ting dep] xejal qil-di? Ahmet [pro which test-from pass-PAST.2sg C ] dream do-PAST.3

Interestingly, verbs of hearing also shift only 1st person indexicals.

angla- (hear) 


\section{Person Indexicals in Uyghur Indexical Shifting}

a. Ahmet Aygül-din [pro qaysi imtihan-din öt-tim dep] angla-di? Ahmet Aygül-from [ pro which test-from pass-PAST.1sgC ] hear-PAST.3 'Which test did Ahmet hear from Aygül that he passed?'

b. *Ahmet Aygül-din [pro qaysi imtihan-din öt-ting dep] angla-di? Ahmet Aygül-from [ pro which test-from pass-PAST.2sgC ] hear-PAST.3

\section{oqu- (read)}

a. Ahmet [ pro qaysi imtihan-din öt-tim dep ] oqu-di? Ahmet [ pro which test-from pass-PAST.1sg C ] read-PAST.3 'Which test did Ahmet hear from Aygül that he passed?'

b. *Ahmet [ pro qaysi imtihan-din öt-ting dep ] oqu-di? Ahmet [pro which test-from pass-PAST.2sg C ] read-PAST.3

We claim that the above restrictions on shifted 2 nd person pronouns follow from the meanings of attitude verbs. Recall that our meaning for tell in (14) quantifies over indices whose first and second coordinates are de se and de te individuals respectively. We assume the same semantics for other verbs of communication, except that they impose different restriction on the possible world coordinate. As explained in the previous section, this semantics together with the definite description analysis of Uyghur 2nd person indexicals predicts obligatory indexical shifting.

Our semantics also explains the infelicity of shifted 2 nd person indexicals under verbs of believing without further ado. That is, in the de re construal, a 2 nd person indexical denotes the individual in the actual world $w_{i}$ that the de se individual $a_{j}$ is talking to in $w_{i}$. However, verbs of believing describe events or states involving just the agent/experiencer without a person who he or she is talking to. Thus there is no individual satisfying the description, and a presupposition failure ensues. The de dicto reading similarly gives rise to a presupposition failure. Likewise, in events describe by verbs of hearing, the de se individual is talking to nobody, and shifted 2nd person indexicals under those verbs are predicted to be infelicitous as well.

\section{$6 \quad$ Anand \& Nevins on Slave}

In this last section, we address one issue of cross-linguistic variation among languages with indexical shifting. It has been observed that languages with indexical shifting differ in whether multiple attitude verbs allow indexical shifting, ${ }^{5}$ and in Amharic, Zazaki, and Matses, unlike in Uyghur, only the verb say triggers indexical shifting. ${ }^{6}$ At this moment, we only know of one language, Slave, that allows for

\footnotetext{
${ }^{5}$ Another cross-linguistic variation among languages with indexical shifting is optionality of indexical shifting: Indexical shifting is optional in Amharic and Zazaki, while it is obligatory in Matses, and as we saw in the present paper, in Uyghur finite complement clauses. Slave is complicated in that it is obligatory only under certain verbs. We have nothing insightful to say about this.

${ }^{6}$ In Navajo, there seems to be an inter-speaker variation (Anand 2006:75).
} 


\section{Yasutada Sudo}

multiple verbs to license indexical shifting. In the rest of this section, we compare Slave and Uyghur and discuss their differences. The Slave data presented in this section are taken from Anand and Nevins (2004) and Anand (2006), who in turn took them from Rice (1986).

Slave imposes restrictions on shifted 1 st and 2 nd person indexicals that are very similar to Uyghur we observed in the previous section. Specifically, both 1st and 2nd person indexicals shift under édedi (tell, ask), while only 1st person indexicals do under hadi (utter; intransitive), yeni̧wę (want, think), and hudeli (want, think).
a. [ segha ráwọdí ] sédi̧di yịlé
[ 1sg-for 2sg-will-buy ] 2sg-tell-1sg PAST
'You told me to buy it for you'
b. Simon [ rásereyineht'u ] hadi
Simon [ 2sg-hit-1sg ] 3sg-say
'Simon said that you hit $\{$ him, *me $\}$ '
c. sú [ leshuyie k'eguhw'e ] yerinewe
$\mathrm{Q}$ [ spoon 1sg-will-lick ] 2sg-want
'Do you want to lick the spoon?'
d. denexare [ woję̧] yeni̧we
sister [2sg-will-sing ] 3sg-want
'Sister wants you to sing'
e. John [ beya ráwozíe ] hudeli
John [ 1sg-son 3sg-will-hunt ] 3sg-want-4sg
'John wants his/my son to go hunting'

Anand and Nevins (2004) and Anand (2006) account for the Slave fact by postulating three kinds of monsters in (33), assuming different attitude verbs select for different monsters. In their analysis, context indices are richer than ours, and the difference between the first two monsters are not directly relevant for our purposes. Also notice that in their semantics the object language does not contain indices, and hence the interpretation function is relativized to two indices $c$ and $i$.
a. $\llbracket \mathrm{OP}_{\forall} \phi \rrbracket_{g}^{c, i}=\llbracket \phi \rrbracket_{g}^{i, i}$
b. $\quad \llbracket \mathrm{OP}_{\text {per }} \phi \rrbracket_{g}^{c, i}=\llbracket \phi \rrbracket_{g}^{\left\langle a_{i}, h_{i}, l_{c}, t_{c}, w_{c}, \ldots\right\rangle, i}$
c. $\llbracket \mathrm{OP}_{\text {auth }} \phi \rrbracket_{g}^{c, i}=\llbracket \phi \rrbracket_{g}^{\left\langle a_{i}, h_{c}, l_{c}, t_{c}, w_{c}, \ldots\right\rangle, i}$

They maintain that verbs that only shift 1 st person indexicals select for the third monster, which only shifts the first individual coordinate of the context index, leaving the other coordinates intact.

Although this account can basically describe the data, however, it has a conceptual weakness, on which Anand (2006:110) himself remarks as follows. 
“[I]t seems rather natural that 'tell' would shift 2nd person while 'want' would not; indeed, what would such a shift mean, given that it is unclear how the ADDR coordinate would even be filled in such cases."

Also, in their analysis, it is in principle possible to define a monster that only shifts the second individual coordinate, but such a shifting pattern has not been found.

Under our analysis, by contrast, only verbs involving an attitude holder and her addressee are predicted to shift both 1 st and 2 nd person indexicals. Also, it is expected that no verbs shift only 2 nd person indexicals because no attitude verbs lack an attitude holder. Thus, our analysis is more constrained than Anand and Nevins' and better on conceptual grounds.

Lastly, we discuss an intriguing difference between Uyghur and Slave, namely, in Slave, 2nd person indexicals under verbs that do not shift them are still felicitous, and interpreted as the hearer of the current context of utterance as shown in (32b), unlike in Uyghur where they are infelicitous. This can be given a straightforward explanation in our analysis by postulating a variation in the interpretation of 2 nd person indexicals. Recall that we proposed that Uyghur 2nd person indexicals are in fact disguised definite descriptions containing a 1st person indexical. We conjecture that Slave 2nd person indexicals are not definite descriptions but directly denote the second individual coordinate $h_{c}$ of the context index $c$. Furthermore, we propose attitude verbs such as think and want just inherit the second individual coordinate from the higher index (cf. the meaning of non-attitude modals in (12)).

(34) For any $\phi$ of type $\langle s, t\rangle$,

$\llbracket$ think $\phi \rrbracket_{g}^{c}=\lambda x . \lambda i . \forall j \in \operatorname{DOX}_{x, i} \llbracket \phi \rrbracket_{g}^{c}(j)=1$

where $j \in \mathrm{DOX}_{x, i}$ iff

a. $w_{j}$ is compatible with what $x$ believes in $w_{i}$;

b. $a_{j}$ is the individual in $w_{j}$ that $x$ identifies in $w_{i}$ as himself;

c. $h_{j}=h_{i}$

(35) For any $\phi$ of type $\langle s, t\rangle$

$\llbracket$ hear $\phi \rrbracket_{g}^{c}=\lambda x . \lambda y . \lambda i \forall j \in \operatorname{HEAR}_{x, y, i} \llbracket \phi \rrbracket_{g}^{c}(j)=1$

where $j \in \operatorname{HEAR}_{x, y, i}$ iff

a. $w_{j}$ is compatible with what $x$ hears from $y$ in $w_{i}$;

b. $a_{j}$ is the individual in $w_{j}$ that $x$ identifies in $w_{i}$ as himself;

c. $h_{j}=h_{i}$

This analysis explains why 2nd person indexicals in Slave under those verbs can still refer to the actual hearer.

It should be pointed out here that this semantic variation in 2 nd person indexicals is independently necessary to account for the difference between Uyghur and languages such as Slave and Zazaki in which shifted 2nd person indexicals are obligatorily de te (Anand 2006). It is predicted therefore that shifted 2nd person index- 


\section{Yasutada Sudo}

icals in Slave are obligatorily de te unlike in Uyghur, but the lack of data prevents us from testing this prediction at this moment. This is left for future research.

\section{Acknowledgments}

I am especially indebted to my language informant, Mettursun Beydulla, for his patience and generosity. I would also like to thank the following people for invaluable discussions and helpful comments: Adam Albright, Pranav Anand, Alya Asarina, Amy Rose Deal, Rose-Marie Déchaine, Michel DeGraff, Suzanne Flynn, Danny Fox, Martin Hackl, Claire Halpert, Irene Heim, Norvin Richards, Andrew Nevins, Philippe Schlenker, Kirill Shklovsky and Martina Wiltschko. My thanks also go to the audience of BLS 36. All errors are mine. (This paper was written in June 2010, four months after the conference. Almost five years have passed since then, and this work has been superseded by my MIT dissertation written in 2012.)

\section{References}

Anand, Pranav. 2006. De De Se. Ph.D. dissertation, MIT.

Anand, Pranav and Andrew Nevins. 2004. Shifty operators in changing context. In Proceedings of SALT 14.

Chierchia, Gennaro. 1989. Anaphora and attitude de se. In Renatte Bartsch, Johan van Benthem, and Peter van Embde Boas, eds., Semantics and Contextual Expression, 1-32, Dordrecht: Foris.

De Jong, Frederick. 2007. A Grammar of Modern Uyghur. Utrecht: Houtsma.

Deal, Amy Rose. 2008. Events in space. In Proceedings of SALT 18.

Gallin, Daniel. 1975. Intensional and Higher-Order Modal Logic. Amsterdam: North-Holand.

Geurts, Bart. 1999. Presuppositions and Pronouns. Amsterdam: Elsevier.

Hahn, Reinhard F. 1991. Spoken Uyghur. Seattle: University of Washington Press.

Kaplan, David. 1989. Demonstratives: An essay on the semantics, logic, metaphysics, and epistemology of demonstratives and other indexicals. In Joseph Almog, John Perry, and Howard Wettstein, eds., Themes from Kaplan, 481-563, New York: Oxford University Press.

Keshet, Ezra. 2008. Good Intensions: Paving Two Roads to a Theory of the De re/De dicto Distinction. Ph.D. thesis, Massachusetts Institute of Technology. 
Leslau, Wolf. 1995. A Reference Grammar of Amharic. Harrassowitz.

Lewis, David. 1979. Attitudes de dicto and de se. Philosophical Review 88(4):513543.

Ludwig, Rainer A., Robert Munro, David W. Fleck, and Uli Sauerland. to appear. Reported Speech in Matses: Obligatory Perspective Shift with Syntactic Transparency. In Proceedings of SULA 5.

Ogihara, Toshiyuki. 2006. Attitudes without monsters: A Japanese perspective. In Proceedings of SALT 16, 156-171.

Percus, Orin. 2000. Constraints on some other variables in syntax. Natural Language Semantics 8:173-229.

Quer, J. 2005. Context shift and indexical variables in sign languages. In SALT 15.

Rice, Keren. 1986. Some remarks on direct and indirect speech in Slave (Northern Athapaskan). In Florian Coulmas, ed., Direct and Indirect Speech, 47-76, Berlin: Mouton de Gruyter.

Schlenker, Philippe. 1999. Propositional Attitudes and Indexicality. Ph.D. dissertation, MIT.

Schlenker, Philippe. 2003. A plea for monsters. Linguistics and Philosophy 26(1):29-120.

Shklovsky, Kirill and Yasutada Sudo. to appear. Indexical Shifting in Uyghur. In Seda Kan, Claire Moore-Cantwell, and Robert Staubs, eds., Proceedings of NELS 40, Amherst, MA: GLSA.

Speas, Margaret. 1999. Person and point of view in Navajo. In WCCFL 18.

von Stechow, Arnim. 2002. Feature deletion under semantic binding. In Proceedings of NELS 33.

von Stechow, Arnim and Thomas Ede Zimmermann. 2005. A problem for a compositional treatment of de re attitudes. In Gregory N. Carlson and Francis Jeffry Pelletier, eds., Reference and Quantification: The Partee Effect, 207-228, Stanford, CA: CSLI.

Yasutada Sudo

Massachusetts Institute of Technology

Department of Linguistics and Philosophy

77 Massachusetts Avenue, 32-D808 
Yasutada Sudo

Cambridge, MA 02139

ysudo@mit.edu 